\title{
Non -Invasive imaging modality in HIV-SGD
}

\author{
Warhekar AM1, Chaudhary $A^{2}$, Wanjari PV ${ }^{3}$, Reddy $V^{4}$, Verma $\mathbf{M}^{5}$, Lalawat $S^{6}$ \\ ${ }^{1}$ Dr. Ashish M Warhekar, Reader, ${ }^{2}$ Dr. Arati Chaudhary, Professor, ${ }^{3}$ Dr P. V Wanjari, Professor \& Head, ${ }^{4}$ Dr. Vanaja \\ Reddy, Reader, ${ }^{5}$ Dr. Mimansha Verma, PG Student, ${ }^{6}$ Dr. Sweety Lalawat, PG Student. All are affiliated with Department \\ of Oral Medicine and Maxillofacial Radiology, Modern Dental College \& Research Centre, Indore, Madhya Pradesh, \\ India.
}

Address for correspondence: Dr. Mimansha Verma, Email: dr.mimansha24@gmail.com

\begin{abstract}
The HIV-infected population is increasing as major health hazard in both developing \& developed countries. In the society, many of children are unaware of HIV or parents refuse to accept the HIV positive status due to social stigma, fear of discrimination \& thus perpetuating the spread of HIV. Painless salivary gland swelling is one of the diagnostic \& prognostic significance in HIV infected children out of which benign lympho-epithelial cyst is earliest manifestation with incidence of $30 \%$. Here, we are highlighting a rare case report of bilateral parotid enlargement in young HIV infected patient.
\end{abstract}

Key words: AIDS, Benign Lympho-epithelial cyst, HIV-SGD.

\section{Introduction}

Human immunodeficiency virus is a lethal virus leading to acquired immune-deficiency syndrome. It is anticipated to have 36.9 million people currently living with HIV \& nearly $38 \%$ of all new infections occur among young people below 25 years .Globally, there were 2.6 million children living with HIV [1]. This viral infection has far reaching implications from dental practitioners on salivary gland manifestation as it has both diagnostic \& prognostic significance.

Human immunodeficiency virus - salivary gland disease (HIV-SGD) includes various salivary gland disorders such as lymphoepithelial lesions, cysts involving the salivary gland tissue and/or intraglandular lymph nodes, parotitis, Sjögren's syndrome-like conditions, diffuse infiltrative lymphocytosis syndrome (DILS) as well as salivary gland neoplasms such as adenoid cystic carcinoma, Kaposi sarcoma and lymphoma [2].

Benign lympho-epithelial cysts is typically an early manifestation \& thought to be localized manifestation of generalized lymphadenopathy in the HIV-positive patient [3] estimated at $6-10 \%$ overall incidence and up to $30 \%$ in Children $[3,4]$. Under this circumstances advanced imaging of salivary gland could reveal significant findings \& would be non invasive \& readily acceptable by the young children which will aid in accurate diagnosis. Here we are highlighting a rare case of bilateral benign lympho-epithelial cyst secondary to HIV in young individual who was diagnosed on the basis of thorough history, Clinical examination, serological testing \& advanced imaging ( USG \& MRI).

\section{Case Report:}

A 15-year-old young female patient reported to Department of Oral Medicine \& Maxillofacial Radiology, Modern Dental College \& Research Centre, Indore, India with a chief complaint of swelling with right \& left check since 4 years. Initially swelling was smaller in size, was gradual in onset $\&$ increased in size during 2 years to achieve present size. There was no history of trauma or pain preceding the swelling. There was no history of paraesthesia, dryness of mouth, dryness in the eyes, difficulty in speaking, swallowing, breathing, difficulty in jaw movements and mouth opening. There was no history of other associated symptoms such as fever, loss of appetite, fatigue, joint pain or loss of weight. Her past

Manuscript received: $14^{\text {th }}$ Jan 2016

Reviewed: $05^{\text {st }} \mathrm{Feb} 2016$

Author Corrected; $17^{\text {th }} \mathrm{Feb} 2016$

Accepted for Publication: 29 $9^{\text {th }}$ Feb 2016 
medical history depicts presence of pneumonia at the age of 4 . There was no history of any other systemic illness. During primary questioning, her parents denied having any major systemic illness. General physical examination revealed a well built and nourished patient with vital signs within satisfactory limits.

A single submandibular, preauricular \& post-auricular lymph-node were palpable, ovoid in shape, non-tender, firm in consistency \& freely mobile.

On extra-oral examination bilateral, sessile, well defined ovoid shaped swelling was present in parotid \& ramus region measuring approximately $6 \times 5 \mathrm{~cm}$ in size. \& extending superio-inferiorly from auricle to $1 \mathrm{~cm}$ below the angle of mandible \& antero-posteriorly from anterior border of ramus to retromandibular area behind ear lobe. Skin over the swelling appeared normal. Right ear lobe was raised. (Fig1) On palpation there was no local rise in temperature, swelling was non tender, non-fluctuant, non-pulsatile, soft to firm in consistency, freely mobile \& non-adherent to underlying bone, non reducible.

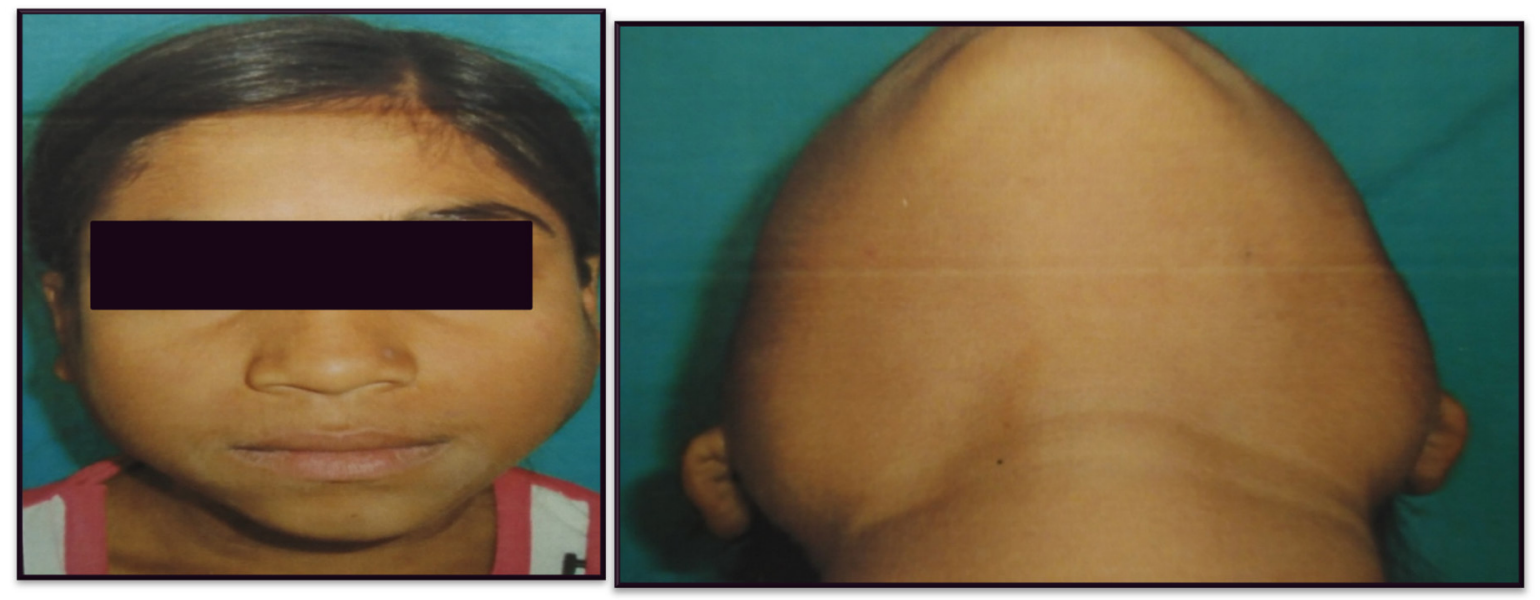

Figure 1: Extra-oral picture showing bilateral swelling in parotid Ramus region.

On intra-oral examination of hard and soft tissues no abnormalities were detected. Right and left Stenson's duct opening was patent, non-inflamed and copious salivary flow was noted. (Fig 2)

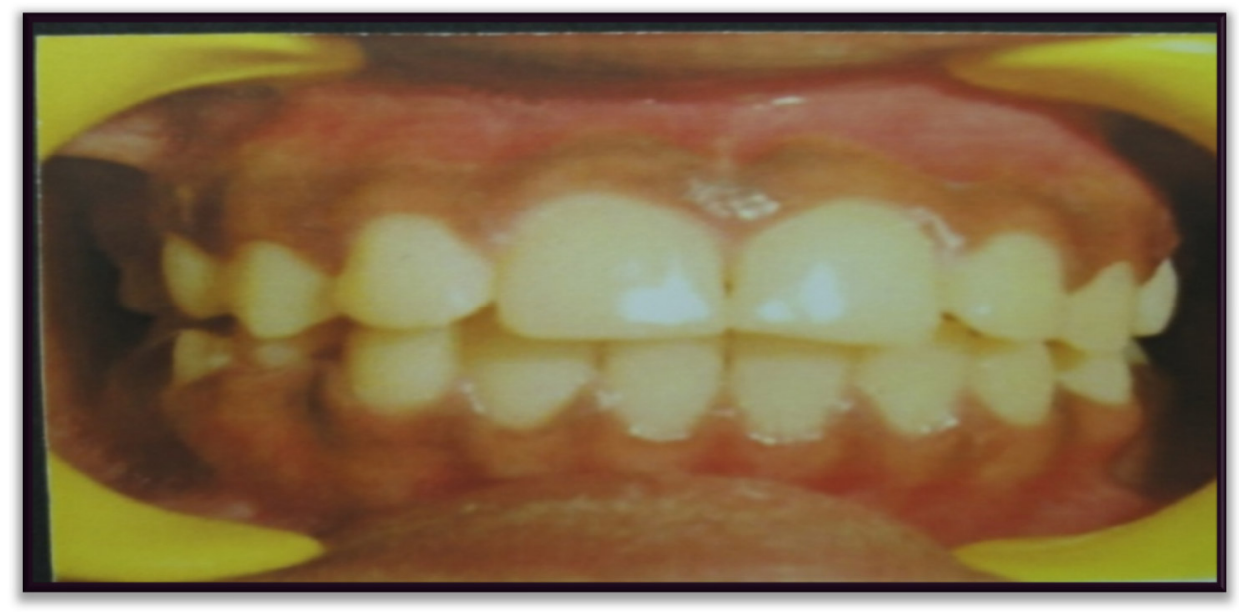

Figure 2: Intra-oral picture showing no abnormality

Based on the history and clinical examination a provisional diagnosis of benign tumor involving parotid gland was made. Then patient was subjected to serological, hematological \& radiological investigations.

Patient hemoglobin was $11.0 \mathrm{~g} \%$, Erythrocyte sedimentation rate was raised $(40 \mathrm{~mm} / \mathrm{hr}) \&$ was positive for HIV antigen. 
Case Report

After serologic evidence, the parents questioned again \& they confessed that they did not reveal their HIV positive status at initial visit. Orthopantamography showed no abnormalities (Fig 3). Ultrasound was done which revealed bilateral multiple cystic lesions replacing the parenchyma of glands (Fig 4).



Figure 3: OPG radiograph shows no abnormalities
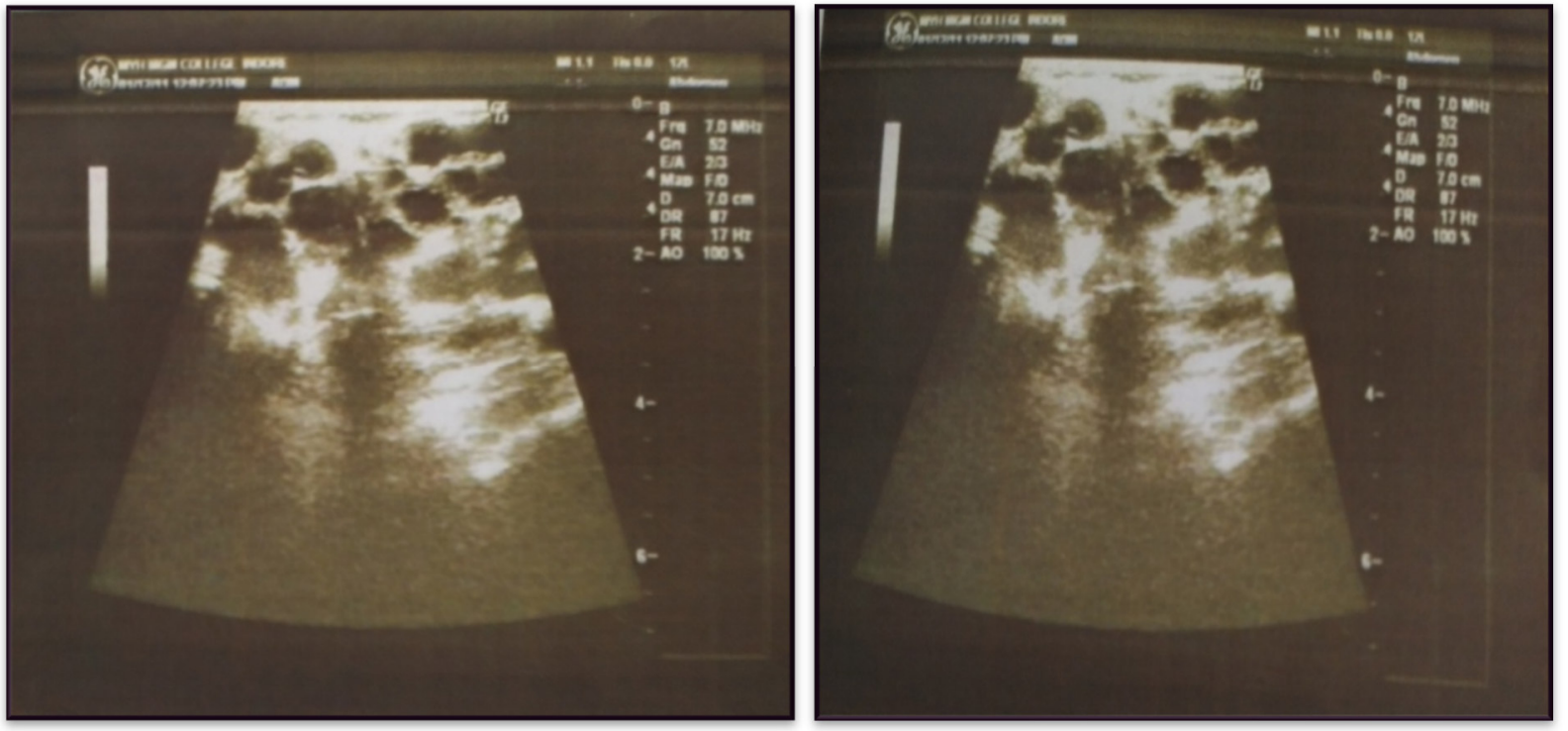

Figure 4: USG showing multiple cystic lesions replacing the parenchyma of glands

Patient was further subjected to MRI for confirmation of the diagnosis \& extension of the lesion . It showed both parotid glands were diffusely enlarged \& there were multiple cysts of varying sizes between 5 to $15 \mathrm{~mm}$, replacing almost entire bilateral parotid parenchyma. Deep lobes were also involved. They appeared hypointense on T1 \& hyper in STIR images. No solid lesion or calcified foci were seen. There were small similar cysts also seen in bilateral submandibular glands which appeared slightly enlarged, Multiple homogenous non necrotic lymph-nodes measuring upto1.5cms were seen. Small sub centimeter sized mental \& submandibular lymph nodes were also seen. (Fig 5).

Based on the history, clinical examination, investigations \& advanced diagnostic imaging modalities a final diagnosis of benign lympho-epithelial cyst secondary to HIV infection was made. Patient was referred to HIV centre of resident medical college for further treatment. 


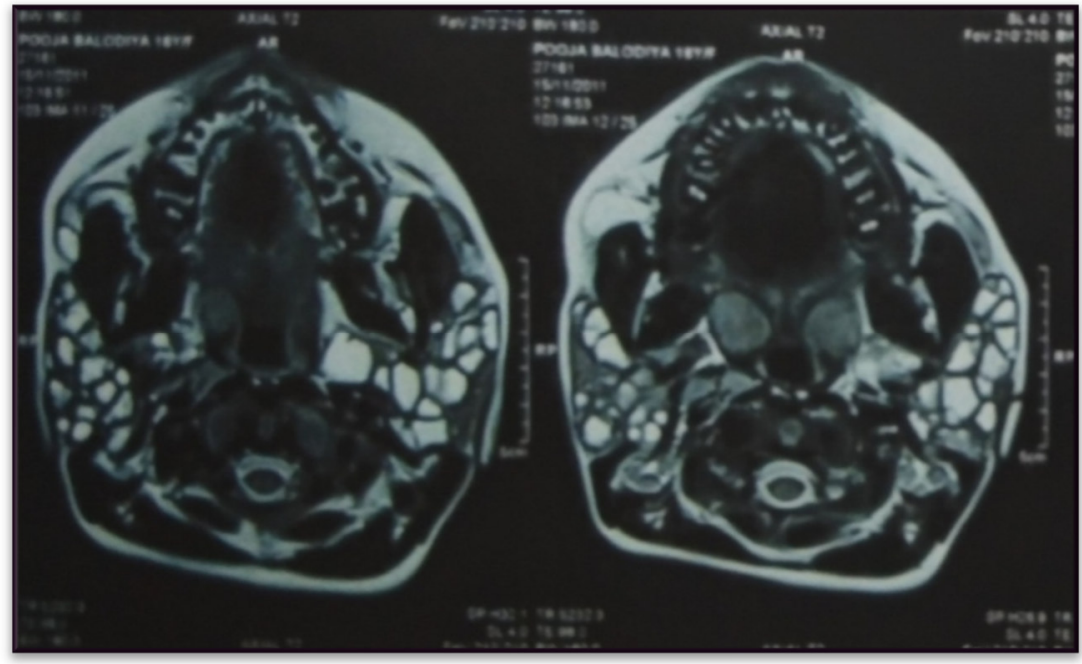

Figure 5: MR image showing diffuse parotid gland enlargement with multiple cystic lesions appears as hypointense on T1 \& hyper in STIR image.

\section{Discussion}

Human immunodeficiency virus is a well known virus that weakens the immune system of the body \& still remains a major public health hazard. AIDS-related stigma and discrimination is especially common in women, makes this disease not accepted it in public. Consequently carry a moral baggage $\&$ thus perpetuate the continuous spread of disease [5]. Neoplastic or Non-neoplastic salivary gland enlargements occur with increased frequency in HIV-infected patients [6] Schiodt et al first described HIV-associated salivary gland disease involving one or both parotid glands with or without xerostomia [7]. Benign lymphoepithelial cysts is typically an early manifestation \& thought to be a localized manifestation of the generalized persistent lymphadenopathy associated with HIV infection $[7,8]$ Hobb et al suggested a three stage classification system which includes Persistent generalized lymphadenopathy (PGL), Benign lympho-epithelial lesions (BLEL) \& Benign lympho-epitheial cysts (BLEC) [4]. The pathophysiology of this disease remains unclear whether lymphoepithelial cysts in parotid glands develop from pre-existing salivary gland inclusions in intra parotid lymph nodes or from a lymphoepithelial lesion of the salivary parenchyma [9]. Ihrler et al. demonstrated a secondary lymphatic infiltration of salivary parenchymal gland which provokes a lymphoepithelial lesion with basal cell hyperplasia of the intercalated ducts. $[8,10]$ The classical presentation of the BLEL include bilateral $(80 \%)$ or unilateral, single or multiple (90\%), painless, soft in consistency and slowly progressive in size [3].It usually involve the superficial lobes of the parotid gland \& may become larger, causing cosmetic embarrassment and social stigma to the patient as seen in our case. To diagnose Lymphoepithelial lesion or cyst necessary investigation and advanced imaging is required which will be helpful for proper diagnosis\& pre-operative treatment planning [11]. Fine Needle Aspiration Cytology serves as both diagnostic \& therapeutic purpose [12] but in our case, patient refused for invasive procedure due to extreme needle phobia. Non-invasive diagnostic evaluation consists of an ultrasound, computed tomography scanning (CT) and/or magnetic resonance imaging (MRI) [7] in cases of diagnostic ambiguity. Ultrasonography is excellent diagnostic imaging modality for evaluating "superficially located anatomic soft tissue entities" such as the parotid gland. Furthermore, its advantages include that it is easy to perform, painless, inexpensive, and readily available and obviates radiation exposure to patients [13]. USG of these lesions reveals diffuse, multiple, hypoechoic or anechoic (cystic) areas, totally or partially replacing the gland parenchyma as reported in present case. MRI is useful in diagnosing the parotid gland lesions owing to its superior soft tissue contrast.MR images shows homogenously hypointense on T1 weighted images \& homogenously hyperintense on $\mathrm{T} 2$ weighted image [7] as reported in present case. Treatment of BLEL include repeated fine-needle aspiration and drainage, surgery, radiotherapy, sclerotherapy, and conservative 
management, with institution of highly active antiretroviral therapy medication [11]. HAART have been documented to decrease the size of lesion \& increase in circulating naïve CD4 and CD8 cells and a decrease in circulating memory CD8 cells [4]. HIV infection predisposes individuals to the risk of lymphoma with dysfunction of the immune system of the body [4]. Sudden changes in gland size omen lymphomatous transformation. Hence, periodic monitoring of these patients is mandatory. The epidemic of fear, stigmatization \& discrimation in the society hinders the acceptance of HIV amongst people, hence contributing increase in population of HIV \& AIDS in India. Parotid gland swelling is typically an earliest manifestation out of which benign lymphoepithelial cyst is commonest in HIV infected children .So we as oral physicians should be able to distinguish it from benign tumors of parotid gland by thorough clinical examination appropriate investigations which will aid in diagnosis and treatment planning.

\section{Funding: Nill, Conflict of Interest: None \\ Permission of IRB: Yes}

\section{References}

1. Kaiser Family Foundation, The Global HIV/AIDS Epidemic Overview; accessed November 2015, available at: kff.org/global-health-policy/fact-sheet/theglobal-hivaids-epidemic/

2.

Shivhare

P, Shankarnarayan L, Jambunath U,Basavaraju SM .Benign lymphoepithelial cysts of parotid and submandibular glands in a HIV-positive patient, J Oral Maxillofac Pathol. 2015 Jan-Apr; 19(1): 107.

3. Jacob LE,Malavika R,Vasudevan V,Kumar MS,Kailasam S.Lymphoepithelial Cyst of the Parotid Gland in an HIV-Positive Patient, Journal of Indian Academy of Oral Medicine and Radiology, JanuaryMarch 2013;25(1):73-76

4. Kungoane T .Lymphoid Proliferation of the Parotid Gland in Paediatric Patients with HIV Infection.
Johannesburg : Faculty of Health Science, University of the Witwatersrand; July 2010.

5. Charles B, Jeyaseelan L, Pandian AK, Sam AE, Thenmozhi M, Jayaseelan V. Association between stigma, depression and quality of life of people living with HIV/AIDS (PLHA) in South India - a community based cross sectional study. BMC Public Health. 2012 Jun 21;12:463. doi: 10.1186/1471-2458-12-463.

6. Greenberb MS, Glick M, Slip JA. Text book of oral medicine burkit. $11^{\text {th }}$ edition.CBS Publishers \& Distributors Pvt Ltd;2012

7. Ebrahim S, Singh B, Ramklass SS. HIV-associated salivary gland enlargement: a clinical review, SADJ. 2014 Oct;69(9):400-3.

8. Sharma G, Nagpal A.Salivary gland disease in human immunodeficiency virus/ acquired immunodeficiency syndrome: A review World J Dermatol 2015 February 2; 4(1): 57-62

9. Kumar VV, Sharma N. Parotid lymphoepithelial cysts as an indicator of HIV infection. J Can Dent Assoc. 2011;77:b28.

10. Owotade FJ, Fatusi OA, Adebiyi KE, Folayan MO.Clinical Experience with Parotid Gland Enlargement in HIV Infection: A Report of Five Cases in Nigeria The Journal of Contemporary Dental Practice, Volume 6, No. 1, February 15, 2005

11. Steehler MK, Steehler MW, Davison SP. Benign lymphoepithelial cysts of the parotid: long-term surgical results. HIV AIDS (Auck1). 2012;4:81-6. doi: 10.2147/HIV.S27755. Epub 2012 May 28.

12. Rojas R, Di Leo J, Palacios E, Rojas I, Restrepo S. Parotid gland lymphoepithelial cysts in HIV infection. Ear Nose Throat J. 2003 Jan;82(1):20-2.

13. Mandel L. Ultrasound findings in HIVpositive patients with parotid gland swellings. J Oral Maxillofac Surg. 2001 Mar;59(3):283-6.

\section{How to cite this article?}

Warhekar AM, Chaudhary A, Wanjari PV, Reddy V, Verma M, Lalawat S. Non -Invasive imaging modality in HIVSGD: Int J Pediatr Res 2016;3(2):130-134. doi:10.17511/ijpr.2016.i02.11. 